\title{
Right Ventricular Histological Substrate and Conduction Delay in Patients With Brugada Syndrome
}

\author{
Kimie Ohкubo, ${ }^{1}$ MD, Ichiro Watanabe, ${ }^{1}$ MD, Yasuo OKumura, ${ }^{1}$ MD, Yasuhiro Takagi, ${ }^{1}$ MD, \\ Sonoko Ashino, ${ }^{1}$ MD, Masayoshi Kofune, ${ }^{1}$ MD, Hidezou Sugimura, ${ }^{1}$ MD, Toshiko NaKai, ${ }^{1}$ MD, \\ Yuji Kasamaki, ${ }^{1} \mathrm{MD}$, Atsushi Hirayama, ${ }^{1} \mathrm{MD}$, and Shin-Ichiro Morimoto, ${ }^{2} \mathrm{MD}$
}

\begin{abstract}
SUMMARY
The reported pathogenesis of Brugada syndrome is phase 2 reentry resulting from shortening of the epicardial action potential duration at the right ventricular outflow tract (RVOT). However, several studies have revealed a high incidence of ventricular late potentials and high rate of ventricular fibrillation (VF) induced by programmed ventricular stimulation (PVS). The aim of the present study was to evaluate the role of slow conduction at the RVOT for the initiation of VF by PVS and any underlying pathological conditions in Brugada syndrome. Endocardial mapping of the RVOT and endomyocardial biopsy of the right ventricle were performed in 25 patients with Brugada syndrome with inducible VF. Late potentials were positive in 11 of the 25 (44\%) patients. Low-amplitude fragmented and delayed electrograms were recorded at the RVOT in 13 of 18 (72.2\%) patients. Histologic examination of the biopsy samples revealed fatty tissue infiltration, interstitial fibrosis, lymphocyte infiltration, and/or myocyte disorganization in 13 patients. Slow conduction at the RVOT may contribute to the induction of VF by PVS in Brugada syndrome. Various pathomorphologic changes may contribute to slow conduction at the RVOT. (Int Heart J 2010; 51: 17-23)
\end{abstract}

Key words: Brugada syndrome, Electrophysiologic study, Delayed potential, RV biopsy

$\mathrm{S}$ ince its identification as a clinical entity, Brugada syndrome has gained worldwide recognition as an important cause of sudden death. ${ }^{1,2)}$ SCN5A gene, which encodes the cardiac sodium channel, has been proven to be involved in $20-30 \%$ of cases, and the disease is inherited in an autosomal dominant fashion. ${ }^{3,4)}$ Its signature is ST segment elevation in right precordial ECG leads and predisposition to malignant ventricular tachyarrhythmias. The two hypotheses on the mechanism of Brugada syndrome that currently receive the widest support from clinical and experimental studies are 1) heterogeneous abbreviation of right ventricular epicardial action potentials ("repolarization disorder" $)^{5)}$ and 2) conduction delay in the right ventricular outflow tract ("depolarization disorder"). ${ }^{6-10)}$ Moreover, recent studies suggest that other derangements may contribute to the pathophysiology of Brugada syndrome, in particular right ventricular structural derangements. ${ }^{11)}$

The aim of this study was to determine whether concealed cardiac abnormalities are present in patients with Brugada syndrome by identifying pathological findings from right ventricular endomyocardial biopsy specimens obtained from patients with the syndrome.

\section{Methods}

Subjects: Twenty-four men and 1 woman (age, $51.0 \pm 13.7$ years, range, 27 - 73 years) with Brugada syndrome who were admitted to Nihon University Hospital for electrophysiologic study between 1996 and 2007 were enrolled in the study. All had inducible ventricular fibrillation (VF). The diagnosis of Brugada syndrome was based on typical electrocardiographic patterns (persistent or transient right precordial ST-segment elevation with or without atypical right bundle branch block). ${ }^{12)}$ Nine patients had episodes of syncope or aborted sudden cardiac death, and 16 were asymptomatic. Three patients had family history of sudden cardiac death (Table I). Routine studies, including cardiac echocardiography and radionucleography, showed no evidence of structural heart disease in any patient.

Signal-averaged electrocardiography: A ventricular signalaveraged electrocardiogram (ART 1200 EPX signalaveraged ECG apparatus, Arrhythmia Research Technology Inc., Austin, TX, USA; noise level $<0.3 \mu \mathrm{V}$, a bidirectional 4-pole Butterworth high pass filter $40 \mathrm{~Hz}$ ) was recorded in all patients. A positive late potential (LP) characterizing Brugada syndrome is defined in our institution as a root mean square voltage of the last $40 \mathrm{msec}<20 \mu \mathrm{V}^{13,14)}$

Cardiac catheterization: All patients underwent cardiac catheterization, coronary angiography, and left and right ventricular angiography.

Electrophysiologic study: All patients gave informed consent for participation in the electrophysiologic study and for endomyocardial biopsy, which were approved by the

From the ${ }^{1}$ Division of Cardiology, Department of Medicine, Nihon University School of Medicine, Tokyo, and ${ }^{2}$ Division of Cardiology, Department of Medicine, Fujita Health University School of Medicine, Aichi, Japan.

Address for correspondence: Ichiro Watanabe, MD, Division of Cardiology, Department of Medicine, Nihon University School of Medicine, 30-1 Oyaguchikami, Itabashi-ku, Tokyo 173-8610, Japan.

Received for publication July 2, 2009.

Revised and accepted August 21, 2009. 
Table I. Patient Characteristics

\begin{tabular}{|c|c|c|c|c|c|c|}
\hline Patient & $\begin{array}{c}\text { Age } \\
\text { (years) }\end{array}$ & Sex & $\mathrm{FH}$ & ECG Type & Symptom & LP \\
\hline 1 & 27 & M & + & I & - & + \\
\hline 2 & 39 & M & - & III & Syncope & - \\
\hline 3 & 45 & M & - & I & - & - \\
\hline 4 & 54 & M & - & II & - & - \\
\hline 5 & 42 & M & - & III & Syncope & - \\
\hline 6 & 53 & M & - & III & Syncope & + \\
\hline 7 & 68 & $\mathrm{M}$ & + & II & Syncope & - \\
\hline 8 & 33 & M & - & I & - & + \\
\hline 9 & 54 & M & - & I & Syncope & + \\
\hline 10 & 66 & M & - & I & - & - \\
\hline 11 & 53 & $\mathrm{M}$ & + & $\mathrm{I}$ & Syncope & - \\
\hline 12 & 29 & M & - & II & - & + \\
\hline 13 & 50 & $\mathrm{~F}$ & - & I & - & - \\
\hline 14 & 73 & M & - & II & - & - \\
\hline 15 & 64 & $\mathrm{M}$ & - & III & - & - \\
\hline 16 & 54 & M & - & II & - & - \\
\hline 17 & 43 & M & - & III & CPA & + \\
\hline 18 & 43 & M & - & III & $\mathrm{CPA}$ & + \\
\hline 19 & 61 & $\mathrm{M}$ & - & III & - & + \\
\hline 20 & 45 & M & - & III & - & + \\
\hline 21 & 28 & M & - & II & - & - \\
\hline 22 & 65 & $\mathrm{M}$ & - & II & - & - \\
\hline 23 & 58 & M & - & I & - & + \\
\hline 24 & 76 & M & - & I & Syncope & + \\
\hline 25 & 52 & M & - & I & - & - \\
\hline
\end{tabular}

FH indicates family history of sudden death; LP, late potential; and CPA, cardiopulmonary arrest.

Clinical Research Committee of Nihon University Hospital. All studies were conducted with patients in the fasting, drug-free state and sedated with midazolam and fentanyl, and programmed electrical stimulation was performed with conventional intracardiac recording and stimulation. ${ }^{15)} \mathrm{A}$ quadripolar catheter and an octapolar catheter were inserted percutaneously through the right femoral vein and advanced under fluoroscopic guidance, initially to the right atrial appendage and the His-bundle region. One steerable catheter was inserted through the left femoral vein and advanced to the right ventricular apex (RVA). Electrophysiologic study included basal measurement of the conduction interval and programmed ventricular stimulation (PVS). The atrio-His interval and the His-ventricular interval were measured during sinus rhythm. The protocol specified 2 sites of ventricular stimulation (the RVA and RVOT), 2 basic cycle lengths (600 and $400 \mathrm{~ms}$ ), and 1 to 3 ventricular premature beats (S2 down to an effective refractory period and $\mathrm{S} 3$ and $\mathrm{S} 4$ down to a minimum of $190 \mathrm{~ms}$ ). At each basic cycle length, programmed stimulation at the RVA was performed first. Ventricular arrhythmia was considered inducible if a sustained ventricular arrhythmia (VF, polymorphic ventricular tachycardia, or monomorphic ventricular tachycardia lasting > 30 seconds or requiring emergency intervention) resulted. A local bipolar electrogram with a $30-500-\mathrm{Hz}$ bandwidth at the right ventricular endocardium was mapped to record delayed potentials (DPs) during sinus rhythm in 18 patients with the use of a quadripolar $6 \mathrm{~F}$ deflectable catheter (EP Technologies, San Jose, CA, USA) by moving the catheter that had been placed at the right atrial appendage. DPs were defined as fragmented local electrograms lasting more than
Table II. Electrophysiologic Data

\begin{tabular}{ccccc}
\hline Patient & VF induction & $\begin{array}{c}\text { RV endo- } \\
\text { cardial DP }\end{array}$ & Therapy & $\begin{array}{c}\text { F/U } \\
\text { (months) }\end{array}$ \\
\hline 1 & RVA & $(+)$ & None & $1^{*}$ \\
2 & RVOT & $(-)$ & Cib, Amio & 131 \\
3 & RVOT & $(+)$ & Amio & 126 \\
4 & RVOT & $(+)$ & Amio & 107 \\
5 & RVOT & $(-)$ & Amio & 89 \\
6 & RVA & $(+)$ & Amio & 89 \\
7 & RVOT & $(-)$ & ICD & 87 \\
8 & RVA & $(-)$ & Amio & 78 \\
9 & RVA, RVOT & $(+)$ & None & 69 \\
10 & RVA, RVOT & $(+)$ & None & 67 \\
11 & RVOT & $(-)$ & ICD & 63 \\
12 & RVA & NA & None & 89 \\
13 & RVOT (S4) & NA & None & 67 \\
14 & RVOT (S4) & $(+)$ & None & 58 \\
15 & RVOT (S4) & NA & None & 55 \\
16 & RVOT (S4) & $(+)$ & None & 58 \\
17 & RVOT & $(+)$ & ICD & 61 \\
18 & RVOT (S4) & NA & ICD & 49 \\
19 & RVOT & NA & None & 49 \\
20 & RVOT & $(+)$ & ICD & 46 \\
21 & RVOT & NA & ICD & 53 \\
22 & RVOT & $(+)$ & ICD & 41 \\
23 & RVOT & $(+)$ & None & 47 \\
24 & RVOT & $(+)$ & ICD & 35 \\
25 & RVOT & NA & None & 32 \\
\hline
\end{tabular}

DP indicates delayed potential; Cib, cibenzoline; Amio, amiodarone; and F/U, follow-up. *means sudden cardiac death.

30 ms after termination of the QRS complex.

Endomyocardial biopsy: Endomyocardial biopsy samples were obtained from the upper septal region of the right ventricle (1 to 3 samples per patient). Myocardial specimens were fixed in $10 \%$ buffered formalin and embedded in paraffin for histologic analysis. Five micron-thick sections were stained with haematoxylin and eosin and examined by light microscopy. Fatty infiltration and interstitial fibrosis were examined at $\times 30$ magnification, myocyte hypertrophy, myocyte degeneration, and arrangement disorder were examined at $\times 100$ magnification, and inflammatory cell infiltration was examined at $\times 250$ and $\times 400$ magnifications.

Statistical analysis: All values are expressed as the mean \pm standard deviation (SD). A $P$ value of less than 0.05 was considered statistically significant. StatView 5.0 software (SAS Institute, Cary, NC, USA) was used for data analysis.

\section{RESUlts}

Electrocardiographic characteristics: Clinical characteristics of the patients are summarized in Table I. The ECG patterns of all patients were diagnostic for Brugada syndrome: spontaneous type 1 ECG pattern, 10 patients (40\%); type 2 ECG pattern, 7 patients (28\%); and type 3 ECG pattern, 8 patients $(32 \%) .{ }^{12)}$ In the 7 patients with a type 2 ECG pattern and 8 patients with a type 3 pattern, the ECG changed to a typical type 1 pattern after intravenous administration of pilsicainide ( $1 \mathrm{mg} / \mathrm{kg}$ in 10 minutes) ${ }^{16-18)}$ The mean QRS duration was $110.8 \pm 21.6 \mathrm{~ms}$. No patient had any features of arrhythmogenic right ventricular cardiomyopathy such 
as $\mathrm{T}$ wave inversion in $\mathrm{V} 1-\mathrm{V} 3$, ventricular ectopy of right ventricular origin, ventricular tachycardia, family history of heart failure, or heart block.

Signal-averaged ECG: According to signal-averaged ECGs, late potentials were positive in $11(44 \%)$ of the 25 patients.

Cardiac catheterization and angiography: No left or right ventriculographic abnormality was found in any patient and the coronary angiography findings were normal in all patients.

Electrophysiologic characteristics: Electrophysiologic data are shown in Table II. The atrio-His and His-ventricular intervals during sinus rhythm were $97.0 \pm 18.1 \mathrm{~ms}$ (70 -131 $\mathrm{ms})$ and $53.8 \pm 13.9 \mathrm{~ms}(30-100 \mathrm{~ms})$, respectively. VF was induced by 2 extrastimuli from the RVA in 4 patients in whom RVOT programmed pacing was not performed, from both the RVA and RVOT in 2 patients, and only from the RVOT in 14 patients, and by 3 extrastimuli from the RVOT in 5 patients. DPs were recorded from the RVOT in 13 of 18 patients $(72.2 \%)$ (Figure 1$)$. Late potentials were positive in 7 of the 13 patients with positive DPs $(53.8 \%)$ and in 1 of the 5 patients without DPs $(20.0 \%)$.

Histology: Histopathologic data are summarized in Table III. Moderate $(++)$ to severe $(+++)$ fatty infiltration, myocyte degeneration, fibrosis, and mild (+) lymphocyte infiltration were considered to be abnormal findings. Moderate $(++)$ to severe $(+++)$ fatty infiltration was observed in 5 patients (Figure 2). Other pathologic changes such as myocyte degeneration $(++)$, fibrosis $(++)$, and lymphocyte infiltration $(+)$ were observed in 4, 4, and 4 patients, respectively (Figures 3,4 , and 5), but we did not detect inflammatory tissue changes. We were unable to find any correlation between clinical phenotype (syncope, aborted sudden death) and electrophysiologic characteristics (ECG type, inducibility of $\mathrm{VF}$, right ventricular endocardial DP) of Brugada syndrome and endomyocardial biopsy findings. However, 1 patient (patient 1) with a family history of sudden death, Brugada type 1 ECG, positive late potential, and endocardial DPs

\section{Patient 1}

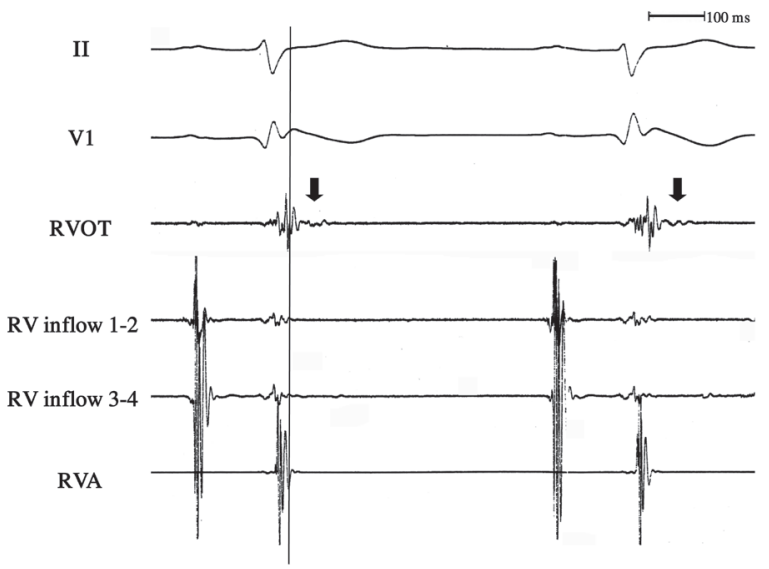

Figure 1. Surface electrocardiographic leads II and V1, intracardiac electrograms from free wall side of the right ventricular outflow tract (RVOT), right ventricular inflow tract, and right ventricular apex (RVA) of patient 1 during sinus rhythm. Note the delayed potentials recorded from the RVOT.

Table III. Histologic Findings

\begin{tabular}{|c|c|c|c|c|c|c|}
\hline Patient & $\begin{array}{c}\text { Myocyte } \\
\text { hypertrophy }\end{array}$ & $\begin{array}{c}\text { Myocyte } \\
\text { degeneration }\end{array}$ & $\begin{array}{c}\text { Arrangement } \\
\text { disorder }\end{array}$ & $\begin{array}{c}\text { Fatty } \\
\text { infiltration }\end{array}$ & $\begin{array}{l}\text { Interstitial } \\
\text { fibrosis }\end{array}$ & $\begin{array}{l}\text { Inflammatory } \\
\text { cell infiltration }\end{array}$ \\
\hline 1 & + & ++ & ++ & & ++ & \\
\hline 2 & & + & + & ++ & ++ & \\
\hline 3 & & + & & & & \\
\hline 4 & + & + & + & & ++ & \\
\hline 5 & + & + & + & & + & \\
\hline 6 & & ++ & + & & ++ & \\
\hline 7 & & + & + & & + & \\
\hline 8 & + & ++ & ++ & & + & + \\
\hline 9 & & ++ & ++ & + & + & \\
\hline 10 & + & + & + & + & & \\
\hline 11 & & + & + & ++ & & \\
\hline 12 & & + & ++ & ++ & + & \\
\hline 13 & & + & + & +++ & + & \\
\hline 14 & & + & ++ & & + & + \\
\hline 15 & & + & + & & + & \\
\hline 16 & & & & + & & \\
\hline 17 & & & & + & + & \\
\hline 18 & + & + & & & & \\
\hline 19 & + & + & & & & \\
\hline 20 & & + & + & & + & + \\
\hline \multicolumn{7}{|l|}{21} \\
\hline 22 & & + & & ++ & + & \\
\hline 23 & + & + & & & & \\
\hline 24 & & & & + & & \\
\hline 25 & + & & & & + & + \\
\hline
\end{tabular}

+ indicates mild change; ++ , moderate change; and +++ , severe change. 


\section{Patient 11}

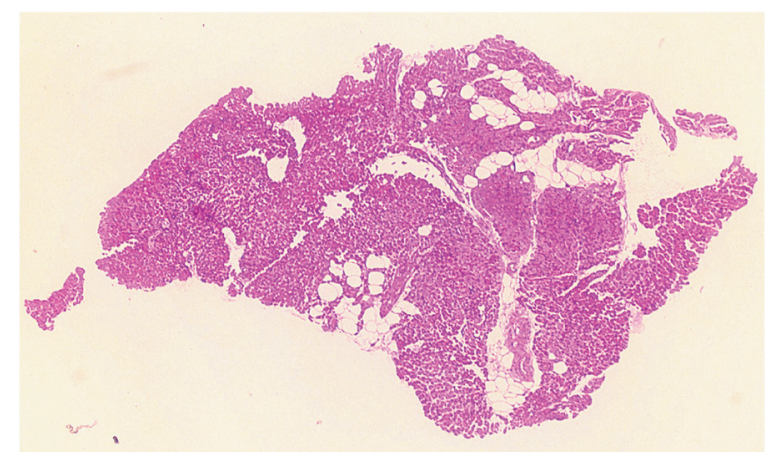

Figure 2. Histopathologic section of the right ventricular septum of patient 11 . Haematoxylin and eosin stain $(\times 20)$. Note the moderate fatty infiltration.

\section{Patient 1}

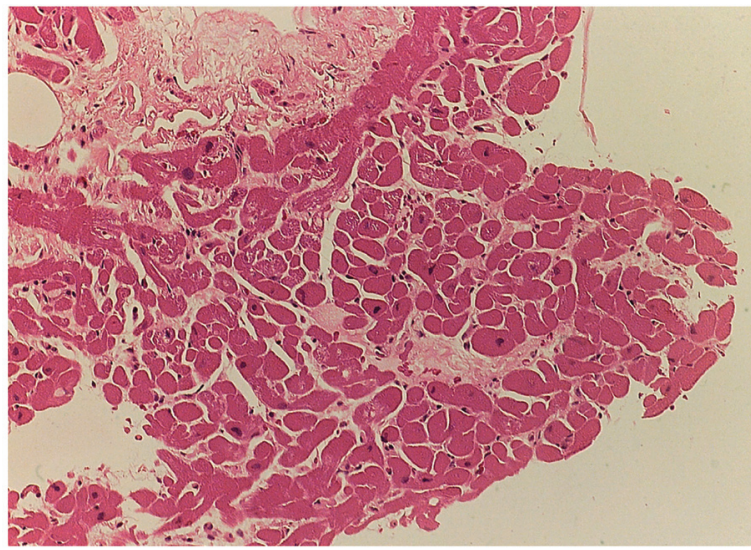

Figure 3. Histopathologic section of the right ventricular septum of patient 1. Haematoxylin and eosin stain $(\times 40)$. Note the myocyte hypertrophy, myocyte degeneration, interstitial fibrosis, and disordered arrangement.

in the RVOT died suddenly. His endomyocardial biopsy specimen showed myocyte degeneration (++), arrangement disorder $(++)$, and moderate interstitial fibrosis $(++)$ (Figures 1 and 3$)$.

Treatment and follow-up: Eight patients received an implantable cardioverter defibrillator (ICD), 6 patients were treated with antiarrhythmic drugs, and 11 patients did not receive any antiarrhythmic treatment (Table II). Patients were followed-up by physical examination, resting electrocardiography, Holter monitoring, 2D echocardiography, and ICD data (for arrhythmic events) retrieval monthly for the first 6 months and every 3 months thereafter. At a median follow-up time of 61.0 months and interquartile range of 39.0 months (range, 1 to 131 months), ICD data retrieval revealed no major arrhythmic event in any patient. One pa-

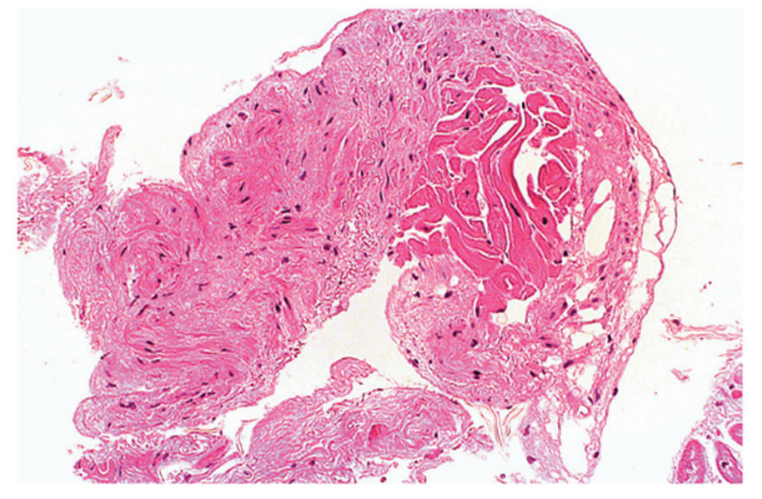

Figure 4. Histopathologic section of the right ventricular septum of patient 4. Haematoxylin and eosin stain $(\times 20)$. Note the marked fibrosis of the myocardium.

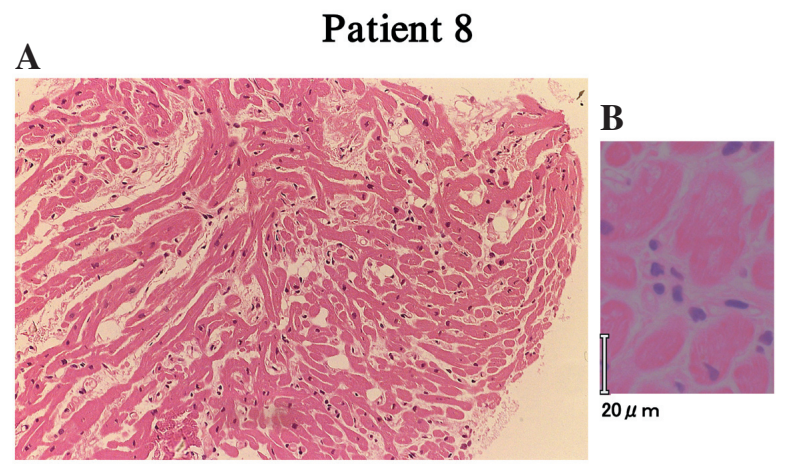

Figure 5. Histopathologic section of the right ventricular septum of patient 8. Haematoxylin and eosin stain. (A) shows myocardial fiber disarray $(\times 40)$, and $(\mathbf{B})$ shows mononuclear cell infiltration $(\times 400)$.

tient who refused an ICD died suddenly during the followup period, whereas no major arrhythmic event occurred in any of the other patients who did not receive an ICD. In 3 symptomatic patients (patients 2, 5, 6) and 3 asymptomatic patients (patients $3,4,8$ ), amiodarone was used for treatment because these patients refused an ICD and the usefulness of quinidine treatment was not well recognized. ${ }^{19)}$

\section{Discussion}

Main findings: In this study, cardiac myocyte hypertrophy $(\geq++)$, myocyte degeneration $(\geq++)$, disordered myocyte arrangement $(\geq++)$, fatty infiltration $(\geq++)$, interstitial fibrosis $(\geq++)$, or inflammatory cell infiltration $(\geq+)$ were found from biopsy samples taken in the right ventricular septum in 13 of 25 (52\%) patients with Brugada syndrome, and LPs were positive in 6 of $13(46 \%)$ of these patients. However, LPs were positive in 5 of $12(42 \%)$ patients with mild histologic findings. DPs were positive in 7 of $10(70 \%)$ 
patients with abnormal histologic findings, but DPs were positive in 6 of $8(75 \%)$ patients with mild histologic findings.

Histology: We have reported that clinically recognized Brugada syndrome may not be a single disease entity and that arrhythmogenic right ventricular cardiomyopathy-like fatty tissue infiltration was seen in at least $30 \%$ of cases in a multicenter study. ${ }^{20)}$ Several studies also revealed histologic abnormalities (fatty infiltration, fatty replacement, fibrofatty replacement) in the right ventricle and suggested an overlap between Brugada syndrome and arrhythmogenic right ventricular cardiomyopathy. ${ }^{6,21-27)}$ Recently, Coronel, et al ${ }^{10)}$ reported on the histopathologic and electrophysiologic characteristics of the heart of a 44-year-old man with genetically proven Brugada syndrome who underwent heart transplantation because of untreatable VF storms. Activation slowing and fractionated electrograms were recorded in the region of the RVOT where histopathologic examination showed epicardial fatty infiltration and extensive fibrosis. Moreover, Frustaci, et $a l^{28)}$ examined the histopathologic substrate in patients with the clinical phenotype of Brugada syndrome by analyzing biventricular endocardial biopsy samples and found prevalent or localized right ventricular myocarditis with detectable viral genomes, right ventricular fibrofatty infiltration, and cardiomyopathic changes. Zumhagen, et al uncovered moderate but uncharacteristic cardiac abnormalities in patients with Brugada syndrome. ${ }^{29)}$ In the present study, at least one of the following was observed in almost all cases; myocardial hypertrophy, myocyte degeneration, arrangement disorder, fatty infiltration, interstitial fibrosis, and lymphocyte infiltration. However, we were unable to find any correlation between the clinical phenotype and electrophysiologic characteristics of Brugada syndrome and endomyocardial biopsy findings. Neither were Frustaci, et al able to correlate the clinical, ECG, and arrhythmic characteristics with histological abnormalities. ${ }^{28)}$ However, they showed that in 3 of 4 patients who were carriers of the SCN5A gene mutation, myocyte cytoplasm degeneration was present upon histologic examination. Furthermore, histopathological examination of the autopsied heart or heart explanted due to cardiac transplantation in patients with Brugada syndrome or right bundle branch block, right precordial ST-segment elevation revealed marked fatty infiltration in the RVOT or right ventricular anterior wall. ${ }^{10,30-32)}$ In previous animal studies, aged heterozygous SCN5A-knockout mice showed impaired atrioventricular conduction, delayed intramyocardial conduction, increased ventricular refractoriness, and ventricular tachycardia associated with myocardial rearrangements and fibrosis. ${ }^{33,34)}$ These studies provided evidence that a monogenic ion channel defect can lead progressively to myocardial structural anomalies. With regard to the possible mechanisms that link sodium channel loss of function to cellular damage, it is well established that intracellular sodium homeostasis has a relevant role in myocardial function, because through the action of sodiumhydrogen and sodium-calcium exchangers, ${ }^{35)}$ it may influence the regulation of both intracellular $\mathrm{pH}$ and calcium homeostasis, ${ }^{35,36)}$ thus impairing excitation-contraction coupling and energy production mechanisms.

Electrophysiologic abnormalities in the RVOT: There is growing clinical evidence for electrophysiologic/structural
RVOT abnormalities in patients with Brugada syndrome. A high proportion of patients with Brugada syndrome have ventricular tachyarrhythmia inducible only from the RVOT, pointing to the importance of the RVOT as a possible site of origin of ventricular tachyarrhythmias. ${ }^{37)}$ The electrical abnormality is localized in the free wall of the RVOT, as suggested by the frequent origin or induction of ventricular arrhythmia from this region, ${ }^{38-41)}$ and Haissaguerre, et al ${ }^{42)}$ showed the importance of focal premature ventricular beats, originating mainly from the RVOT, in triggering VF in patients with Brugada syndrome. Several studies based on noninvasive techniques have shown right ventricular abnormalities in patients with the clinical phenotype of Brugada syndrome. Takagi, et $a l^{43,44)}$ and Sato, et $a l^{45)}$ revealed right RVOT and right ventricular inferior wall motion abnormalities in patients with Brugada syndrome by means of electron beam computed tomography or magnetic resonance imaging. Alix, et $a l^{46)}$ and Papavassiliu, et al $^{47)}$ showed regional dyskinesia and adipose tissue infiltration in the right ventricle by means of magnetic resonance imaging. Nagahara, et $a l^{48)}$ reported frequent detection of myocardial abnormalities in the right ventricle by means of right ventricular myocardial scintigraphy (RV-SPECT) and showed that the arrhythmogenic substrate detected by RV-SPECT can contribute to focal repetitive firing, which degenerates nonself-terminating VF induced by PVS. Furthermore, Tukkie, et $a l^{8)}$ demonstrated, using tissue Doppler echocardiography, that the occurrence of a positive response (covedtype ST elevation) after administration of the class Ic antiarrhythmic drug flecainide coincides with delayed onset of right ventricular contraction, that the extent of the delay correlates with the magnitude of ST elevation, and that right ventricular ejection time shortens as the Brugada ECG pattern emerges. Invasive cardiac studies, including coronary and biventricular angiography with endomyocardial biopsy and 3-dimensional electroanatomical mapping may provide relevant diagnostic information but are rarely applied systematically in patients with the clinical phenotype of Brugada syndrome. Corrado, et al $^{49)}$ and Postema, et al ${ }^{50)}$ revealed a low-voltage area with fractionated electrograms in the RVOT by 3-dimensional electroanatomic voltage mapping.

Study limitations: We obtained endomyocardial biopsy samples only from the septal region of the right ventricle. Previous postmortem histopathologic studies in sudden death victims who had right precordial ST-segment elevation, either isolated or associated with right bundle branch block, revealed predominant fibrofatty replacement in the right ventricular free wall. ${ }^{20,21)}$ Moreover, Coronel, et al ${ }^{10)}$ conducted morphometric analysis of intramyocardial adipose tissue and fibrosis from an explanted heart in a patient with Brugada syndrome who underwent cardiac transplantation and showed that intramyocardial fibrosis and adipose tissue content were greater in the RVOT and lateral wall of the right ventricle than in the left ventricle and septal myocardium. Our findings are consistent with theirs. We did not compare electrophysiologic characteristics of the RVOT and endomyocardial biopsy in patients with Brugada syndrome without inducible VF and control patients. However, it was very difficult to obtain endomyocardial biopsy from "control" patients. We did not analyze the genotypes of SCN5A 
mutations in this study, however, since SCN5A mutations are reported to be involved in $20-30 \%$ of cases of Brugada syndrome, it might be difficult to correlate the genotype mutation, and electrophysiologic and histological findings.

Conclusions: We have provided evidence that symptomatic or asymptomatic patients with Brugada syndrome in whom VF can be induced by PVS despite an apparently normal heart upon clinical, echocardiographic, and angiographic examination have concealed structural abnormalities in the right ventricle. Thus, structural abnormalities in the right ventricle may be the cause of positive late potentials on the signal-averaged ECG and delayed and fragmented potentials recorded from the RVOT.

\section{REFERENCES}

1. Brugada P, Brugada J. Right bundle branch block, persistent ST segment elevation and sudden cardiac death: a distinct clinical and electrocardiographic syndrome. A multicenter report. J Am Coll Cardiol 1992; 20: 1391-6.

2. Antzelevitch C, Brugada P, Brugada J, et al. Brugada syndrome: a decade of progress. Circ Res 2002; 91: 1114-8. (Review)

3. Chen Q, Kirsch GE, Zhang D, et al. Genetic basis and molecular mechanism for idiopathic ventricular fibrillation. Nature 1998; 392: 293-6.

4. Priori SG, Napolitano C, Gasparini M, et al. Natural history of Brugada syndrome: insights for risk stratification and management. Circulation 2002; 105: 1342-7.

5. Li GR, Feng J, Yue L, Carrier M. Transmural heterogeneity of action potentials and Ito1 in myocytes isolated from the human right ventricle. Am J Physiol 1998; 275: H369-77.

6. Corrado D, Basso C, Buja G, Nava A, Rossi L, Thiene G. Right bundle branch block, right precordial st-segment elevation, and sudden death in young people. Circulation 2001; 103: 710-7.

7. Nagase $\mathrm{S}$, Kusano KF, Morita $\mathrm{H}$, et al. Epicardial electrogram of the right ventricular outflow tract in patients with the Brugada syndrome: using the epicardial lead. J Am Coll Cardiol 2002; 39: 1992-5.

8. Tukkie R, Sogaard P, Vleugels J, de Groot IK, Wilde AA, Tan $\mathrm{HL}$. Delay in right ventricular activation contributes to Brugada syndrome. Circulation 2004; 109: 1272-7.

9. Kasanuki H, Ohnishi S, Ohtsuka M, et al. Idiopathic ventricular fibrillation induced with vagal activity in patients without obvious heart disease. Circulation 1997; 95: 2277-85.

10. Coronel R, Casini S, Koopmann TT, et al. Right ventricular fibrosis and conduction delay in a patient with clinical signs of Brugada syndrome: a combined electrophysiological, genetic, histopathologic, and computational study. Circulation 2005; 112: 2769-77.

11. Meregalli PG, Wilde AA, Tan HL. Pathophysiological mechanisms of Brugada syndrome: depolarization disorder, repolarization disorder, or more? Cardiovasc Res 2005; 67: 367-78. (Review)

12. Wilde AA, Antzelevitch C, Borggrefe M, et al. Proposed diagnostic criteria for the Brugada syndrome. Eur Heart J 2002; 23: 1648-54. (Review)

13. Ikeda T, Sakurada H, Sakabe K, et al. Assessment of noninvasive markers in identifying patients at risk in the Brugada syndrome: insight into risk stratification. J Am Coll Cardiol 2001; 37: 1628-34

14. Masaki R, Watanabe I, Nakai T, et al. Role of signal-averaged electrocardiograms for predicting the inducibility of ventricular fibrillation in the syndrome consisting of right bundle branch block and ST segment elevation in leads V1-V3. Jpn Heart J 2002; 43: 367-78
15. Brugada P, Green M, Abdollah H, Wellens HJ. Significance of ventricular arrhythmias initiated by programmed ventricular stimulation: the importance of the type of ventricular arrhythmia induced and the number of premature stimuli required. Circulation 1984; 69: 87-92.

16. Shimizu W, Antzelevitch C, Suyama K, et al. Effect of sodium channel blockers on ST segment, QRS duration, and corrected QT interval in patients with Brugada syndrome. J Cardiovasc Electrophysiol 2000; 11: 1320-9.

17. Morita H, Morita ST, Nagase S, et al. Ventricular arrhythmia induced by sodium channel blocker in patients with Brugada syndrome. J Am Coll Cardiol 2003; 42: 1624-31.

18. Chinushi M, Komura S, Izumi D, et al. Incidence and initial characteristics of pilsicainide-induced ventricular arrhythmias in patients with Brugada syndrome. Pacing Clin Electrophysiol 2007; 30: 662-71.

19. Belhassen B, Glick A, Viskin S. Efficacy of quinidine in highrisk patients with Brugada syndrome. Circulation 2004; 110 : 1731-7. (Review)

20. Morimoto S, Uemura A, Watanabe E, et al. A multicentre histological study of autopsied and biopsied specimens in Brugada syndrome. Eur Heart J 2003; 24(Suppl): 147.

21. Corrado D, Nava A, Buja G, et al. Familial cardiomyopathy underlies syndrome of right bundle branch block, ST segment elevation and sudden death. J Am Coll Cardiol 1996; 27 : 443-8.

22. Tada H, Aihara N, Ohe T, et al. Arrhythmogenic right ventricular cardiomyopathy underlies syndrome of right bundle branch block, ST-segment elevation, and sudden death. Am J Cardiol 1998; 81: 519-22.

23. Morgera T, Sinagra GF, Viel E, Ricci C, Bussani R, Camerini F. The syndrome of right bundle branch block, persistent ST segment elevation and sudden cardiac death. Which is the histological substrate? Eur Heart J 1997; 18: 1190-1.

24. Corrado D, Basso C, Buja GF, Nava A, Thiene G. Electrocardiographic and pathologic correlations in the syndrome of right bundle-branch block, right precordial ST-segment elevation, and sudden death. Eur Heart J 1998; 19(Suppl): 577.

25. Izumi T, Ajiki K, Nozaki A, et al. Right ventricular cardiomyopathy showing right bundle branch block and right precordial ST segment elevation. Intern Med 2000; 39: 28-33.

26. Wichter T, Meyborg M, Paul M, et al. Autonomic dysfunction in Brugada syndrome: New evidence for impaired adrenergic stimulation from biochemical analyses of endomyocardial biopsies. Heart Rhythm 2004; 1(Suppl): S124.

27. Pérez Riera AR, Antzelevitch C, Schapacknik E, Dubner S, Ferreira C. Is there an overlap between Brugada syndrome and arrhythmogenic right ventricular cardiomyopathy/dysplasia? J Electrocardiol 2005; 38: 260-3. (Review)

28. Frustaci A, Priori SG, Pieroni M, et al. Cardiac histopathologic substrate in patients with clinical phenotype of Brugada syndrome. Circulation 2005; 112: 3680-7.

29. Zumhagen S, Spieker T, Rolinck J, et al. Absence of pathognomonic or inflammatory patterns in cardiac biopsies from patients with Brugada syndrome. Circ Arrhythmia Electrophysiol 2009; 2: 16-23.

30. Morimoto S, Uemura A, Hishida H. An autopsy case of Brugada syndrome with significant lesions in the sinus node. J Cardiovasc Electrophysiol 2005; 16: 345-7.

31. Corrado D, Basso C, Buja G, Nava A, Rossi L, Thiene G. Right bundle branch block, right precordial st-segment elevation, and sudden death in young people. Circulation 2001; 103: 710-7.

32. Hoogendijk MG, Potse M, Linnenbank AC, et al. Brugada-type ST segment elevation after sodium channel blockade is caused by right ventricular excitation failure in discontinuous myocardium. Circulation 2008; 118: S_982.

33. Papadatos GA, Wallerstein PM, Head CE, et al. Slowed conduction and ventricular tachycardia after targeted disruption of the cardiac sodium channel gene Scn5a. Proc Natl Acad Sci U S A 2002; 99: 6210-5. 
34. Royer A, van Veen TA, Le Bouter S, et al. Mouse model of SCN5A-linked hereditary Lenègre's disease: age-related conduction slowing and myocardial fibrosis. Circulation 2005; 111: 1738-46.

35. Pieske B, Houser SR, Hasenfuss G, Bers DM. Sodium and the heart: a hidden key factor in cardiac regulation. Cardiovasc Res 2003; 57: 871-2.

36. Bers DM, Barry WH, Despa S. Intracellular $\mathrm{Na}^{+}$regulation in cardiac myocytes. Cardiovasc Res 2003; 57: 897-912. (Review)

37. Eckardt L, Kirchhof P, Schulze-Bahr E, et al. Electrophysiologic investigation in Brugada syndrome; yield of programmed ventricular stimulation at two ventricular sites with up to three premature beats. Eur Heart J 2002; 23: 1394-401.

38. Ohkubo K, Watanabe I, Takagi Y, et al. Electrocardiographic and electrophysiologic characteristics in patients with Brugada type electrocardiogram and inducible ventricular fibrillation: single center experience. Circ J 2007; 71: 1437-41.

39. Morita H, Fukushima-Kusano K, Nagase S, et al. Site-specific arrhythmogenesis in patients with Brugada syndrome. J Cardiovasc Electrophysiol 2003; 14: 373-9.

40. Ohkubo K, Watanabe I, Takagi Y, et al. Surface and intracardiac electrogram characteristics of induced ventricular tachyarrhythmias before degenerating into ventricular fibrillation in Brugada syndrome. Heart Rhythm 2007; 4(Suppl): S196.

41. Ohkubo K, Watanabe I, Takagi Y, et al. Endocardial electrograms from the right ventricular outflow tract after induced ventricular fibrillation in patients with Brugada syndrome. Circ J 2007; 71: 1258-62.

42. Haissaguerre M, Extramiana F, Hocini M, et al. Mapping and ablation of ventricular fibrillation associated with long-QT and Brugada syndromes. Circulation 2003; 108: 925-8.
43. Takagi M, Aihara N, Kuribayashi S, et al. Localized right ventricular morphological abnormalities detected by electron-beam computed tomography represent arrhythmogenic substrates in patients with the Brugada syndrome. Eur Heart J 2001; 22: 1032-41.

44. Takagi M, Aihara N, Kuribayashi S, et al. Abnormal response to sodium channel blockers in patients with Brugada syndrome: augmented localized wall motion abnormalities in the right ventricular outflow tract region detected by electron beam computed tomography. Heart 2003: 89: 169-74.

45. Sato Y, Kato K, Hashimoto M, et al. Localized right ventricular structural abnormalities in patients with idiopathic ventricular fibrillation: magnetic resonance imaging study. Heart Vessels 1996; 11: 100-3.

46. Alix D, Mairesse D, Lacroix D, et al. Right bundle-branch block with ST-segment elevation: evidence for an underlying pathological substrate. Eur Heart J 2003; 24: 195.

47. Papavassiliu T, Wolpert C, Flüchter S, et al. Magnetic resonance imaging findings in patients with Brugada syndrome. J Cardiovasc Electrophysiol 2004; 15: 1133-8.

48. Nagahara D, Uno K, Shimoshige S, et al. Focal myocardial arrhythmogenic substrates detected in Brugada syndrome can contribute to characteristic propagating mode of induced ventricular fibrillation. Circ J 2003; 67 (Suppl 1): 104.

49. Corrado D, Basso C, Thiene G. Is it time to include ion channel diseases among cardiomyopathies? J Electrocardiol 2005; 38: 81-7. (Review)

50. Postema PG, van Dessel PF, de Bakker JM, et al. Slow and discontinuous conduction conspire in Brugada syndrome: a right ventricular mapping and stimulation study. Circ Arrhythmia Electrophysiol 2008; 1: 379-86. 